\title{
A Study on SWOT Analysis of Pharmaceutical Industry: The Bangladesh Context
}

\author{
Meem Rafiul Hoq ${ }^{1}$, Md. Ali Ahsan ${ }^{2}$, Tanim - A - Tabassum ${ }^{3}$ \\ ${ }^{1}$ Lecturer, School of Business, UITS, Bangladesh \\ ${ }^{2}$ Lecturer, School of Liberal Arts \& Science, UITS, Bangladesh \\ ${ }^{3}$ BBA, Asian University of Bangladesh, Dhaka, Bangladesh
}

\begin{abstract}
Pharmaceutical industry is one of the most important sector in Bangladesh. It is the only industry, which has its own strong manufacturing capabilities to produce the pharmaceuticals product. In this study it is tried to find out what types of strengths, weaknesses, opportunities and threats the pharmaceuticals companies face in Bangladesh. There are about 250 pharmaceuticals firms in Bangladesh. Among them some companies are the large size and more sophisticated. Some companies are small sizes and traditional qualities. A few companies dominate the whole medicine market. So they have to face severe competition in pharmaceuticals market.

SOWT (Strength, Opportunity, Weakness, and Threat) analysis of any industry sector investigates the important factors that are possibility of the industry and influencing the companies operating in that sector. The purpose of this study is to analyze the pharmaceutical sector of Bangladesh using the framework of SWOT. This paper brings to light on the SWOT analysis of pharmaceuticals industry in Bangladesh and provided some valuables suggestions to overcome the weaknesses and threats, there are some suggestions to utilize the strengths and opportunities properly. Through this study the researchers try to discuss the affect of various macroeconomic factors of strength, opportunity, weakness, and threat aspect on the industry and its related problems and prospects for the future.
\end{abstract}

Key Words: Pharmaceutical Industry, SWOT, Economic Factor

JEL Classification Code: O25; O25

\section{INTRODUCTION}

Pharmaceutical is the core of Bangladesh's healthcare sector and serves as one of the most important manufacturing industry. With a history since 1950s, the industry has now turned one of the most successful pharmaceuticals manufacturing industry among the developing countries. Presently, the industry meets $97 \%$ of local demand and exports to more than 80 countries. The industry has been experiencing robust growth over the last few years. A local industry supporting drug policy and effective regulatory framework, along with TRIPS (Trade Related Intellectual Property Rights) relaxations are the key reasons for success of the industry. While the industry is achieving self sufficiency, it yet 
procures $70 \%$ of raw materials from abroad. But developments are already taking place, with a number of firms now manufacturing raw materials locally. In addition, an API (Active Pharmaceutical Ingredient) project has already been undertaken to accelerate the vertical integration within the industry. The industry has been expanding locally and internationally. Local market grew at 23\% in 2010, while import reached USD 50 Million landmark. A number of firms got accreditations from USA, UK, and Australia etc. ${ }^{1}$

\section{ObJectives OF The Study}

The study is aimed to fulfill the following specific objectives-

- To key out the major achievements of the Pharmaceutical Industry of Bangladesh.

- To critically analyze the SWOT analysis of the Pharmaceutical Industry of Bangladesh.

\section{Methodology of the Study}

This article is mainly based on secondary data collected from several reliable sources. For secondary data collection, Pharmaceutical Industries' annual reports, exiting files and documents, statements, brochures, manuals and publications were collected and analyzed. An intensive study on the relevant field was conducted through browsing internet and searching in library.

\section{JUSTIFICATION OF THE STUDY}

In Bangladesh the pharmaceutical sector is one of the most developed hi-tech sectors within the country's economy. After the promulgation of Drug Control Ordinance - 1982, the development of this sector was accelerated. The professional knowledge, thoughts and innovative ideas of the pharmaceutical professionals working in this sector are the key factors for these developments. Due to recent development of this sector it is exporting medicines to global market including European market. This sector is also providing $97 \%$ of the total medicine requirement of the local market. Leading pharmaceutical companies are expanding their business with the aim to expand export market. Recently few new industries have been established with high tech equipments and professionals which will enhance the strength of this sector ${ }^{2}$. As a promising sector for a developing country like Bangladesh, pharmaceutical industry is one of the key issues of the country. This field really needs some empirical study like this for the future development.

\section{LIMITATIONS OF THE STUDY}

- It was not possible to study all the relevant literatures.

- Limited time frame was the major constraint to carry out the research smoothly.

- Insufficient previous research works in this field is one of the major limitations of the study.

\section{REVIEW OF LITERATURE}

Habib et al. (2011) reported through their paper that the aim of the study is to present the current scenario of the pharmaceutical industry in Bangladesh. Since inception, there was little consensus on the development of pharmaceutical policies best suited in a developing country such as Bangladesh. Here, the pharmaceutical industry developed rapidly from the 1980s after the introduction of Drug (Control) Ordinance-1982. Adequate infrastructure and use of trained manpower were two essential requisites for 
implementation of national pharmaceutical policies in Bangladesh. The country was importing significant amount of medicine and also raw materials for the industry from abroad. But the industry has started to export its products in foreign market, especially in the Middle East and Europe with great success. This study tries to identify the major problems of marketing, exporting, production and operations, quality control in the pharmaceutical sector and proposes strategies to overcome these problems; it also identifies the prospects of pharmaceutical industry in Bangladesh. ${ }^{3}$

Bhuiyan et al. (2011) in an article named "Analysis of Pharmaceuticals Industry of Bangladesh: It's Challenges and Critical Success Factors" stated that the pharmaceutical industry is globally known as the fastest growing industry in the world. With revenues of USD 518 billion and 9\% of global GDP in the year 2007, pharmaceuticals have a reputation for having the highest profit margin in the world. Bangladesh processes a sizeable pharmaceutical industry that has the potential to live up the global standards. The country can expand it's economic growth by investing in their fast growing pharmaceutical industry which has an annual average growth rate of $16 \%$ and a market size of BDT 30 billion 2007 according to Industrial Management System (IMS). It employees around 75,000 skilled and unskilled employees and is considered to be the second largest contributor to country's national revenue (Bangladesh Gazette). This sector is the second largest contributor to the Government exchequer, employing around 75,000 skilled and unskilled employees. With huge demand-supply gap, major players see basic chemicals as the greatest opportunity for expansion and better control over formulation industry force. ${ }^{4}$

\section{Results AND Discussion}

There are great opportunities for pharmaceutical industry in Bangladesh. Among the LDCs, Bangladesh is the only country that has its manufacturing capabilities to manufacture the pharmaceuticals products. It is found that some manufacturing companies export medicines and earn enough foreign currency. Some companies have world-class pharmaceuticals productions units. Some companies produce world-renowned products in Bangladesh. Some company introduces mattered dose inhalation aerosols by commissioning of its state of the art MDI plant. The MDI plant has been designed in a way to ensure highest possible quality at every stage of manufacturing and quality control. It is found that there are great demands for the pharmaceuticals products in Bangladesh. Increased market complexity now a day's places great demand on the sales and marketing operations of pharmaceutical companies, making it even more difficult to manage.

Some of the major achievements of Bangladesh Pharmaceutical Industry so far are:

1. Affordability of medicines to the majority of the population: Major epidemics of Bangladesh are Malaria including Dengue, Cholera and Typhoid. Morbidity and mortality from these scourges also reduced substantially over the years in Bangladesh. Increased affordability and availability of medicines has contributed towards this achievement. Bangladesh now has an average life expectancy of 61 years, which is at the top end in the Indian sub-continent.

2. Near Self Sufficiency in Pharmaceuticals manufacturing: Among the LDC's, Bangladesh is the only country which can boast a local pharmaceutical industry which caters to $97 \%$ of the countries need. Over the years role of import has diminished substantially and now is not more than 3\% covering mainly Insulin, Vaccines and anti-cancer drugs. 
3. Strong footing of the local Industry: In 1982 there were about 10 multinational companies availing about $80 \%$ of the domestic market. The situation is reverse now. Local companies cater to about $80 \%$ of the market now and the rest by the multinational. Local companies continued their expansions and up gradation of their facilities conforming to cGMP prescribed by WHO and by some leading companies to US FDA and UK MHRA standards.

4. Export of Pharmaceuticals: After catering to the country's need pharmaceutical products from Bangladesh are now being exported to over 62 countries in Asia, Africa and Europe.

5. Quality Assurance: A few of the top-level pharmaceutical companies are going beyond WHO and cGMP. With an aim to get into the regulated markets like US, EU countries etc, they are putting up Government of Bangladesh is very supportive to the industry and is in the process of implementing a new law to face the present and future challenges of the industry.

Pharmaceuticals export has a bright future for Bangladesh and local companies are already competing with the pharmaceuticals from developing countries in Africa and South East Asia. Government is very supportive to these efforts and is planning to set up an Industrial park for Active Pharmaceutical Ingredients (API) to strengthen its position in this area.

Bangladesh pharmaceutical industry's progress so far is praise worthy. It has made the country near self sufficient in pharmaceuticals, became the $2^{\text {nd }}$ largest contributor to government exchequer and is now a major employer of the knowledge based workers. Made pharmaceuticals accessible \& affordable to the majority of the population and forayed into export markets with successful manufacturing facilities of US FDA and UK MHRA standards.

Pharmaceutical Industry of Bangladesh is a unique example of private sector success in the country. After the laudable role it played in domestic market, it is now poised to play its role in the international arena. With its continued development and experience in manufacturing and marketing, it is sure to repeat its success in the international market as well. ${ }^{5}$

\section{MAJOR FINDINGS}

The SWOT analysis of the industry reveals the position of the Bangladesh pharmaceutical industry in respect to its internal and external environment.

\section{Strengths}

1. The growth of middle class in the country has resulted in fast changing lifestyles in urban and to some extent rural centers. This opens a huge market for lifestyle drugs, which has a very low contribution in the Bangladesh market.

2. Bangladesh pharmaceutical manufacturers are one of the lowest cost producers of drugs in the world. With a scalable labor force, Bangladesh manufacturers can produce drugs at $40 \%$ to $50 \%$ of the cost to the rest of the world. In some cases, this cost is as low as $90 \%$.

3. Most of the companies have own premises, so most companies can save their expenses; most pharmaceutical companies have a large size of factory.

4. Excellent transport-link the ease of access to / from the company.

5. Some companies have a good reputation in the market. Some companies have strong brand reputation in the market, these industries have well known brand in the market.

6. Bangladeshi pharmaceutical industry posses' excellent chemistry, skilled workforce and process reengineering skills. This adds to the competitive advantage of the Bangladeshi companies. The strength in chemistry skill helps Bangladeshi companies to develop processes, which are cost effective. 
7. The pharmaceuticals industry has MIS system. These companies have knowledge about diseases, which are available in our country. Most of the companies are more sophisticated. They are more concern or aware about each other.

8. The pharmaceutical companies follow the relationship selling method. The company representatives try to motivate the doctors to prescribe their medicine for the patients. The medical representatives of the pharmaceutical companies maintain the relationship with the doctors.

9. The pharmaceutical industry has the loyalty of the customers and vendors. Drug is essential for life. So these companies have certain markets to sell the medicines in Bangladesh.

10. These industries have some competitive advantages over the other industries. The pharmaceutical industries have strong manufacturing capacities.

11. Most of the companies have the quality control system. They are committed to formulate and supply drugs and formulations in a qualified manner.

12. The growth rate of the pharmaceutical industry is increasing day by day. It is good news for the pharmaceutical industry in Bangladesh.

13. Some companies of the pharmaceuticals industry have got the license of the global brand. Such as Healthcare Pharmaceuticals Company limited manufacture the brands of the F. Hoffmann-La Roche limited.

14. Latest technologies are installed in the pharmaceuticals sector in Bangladesh. Some companies in our country got the technical guidance from the globally reputed pharmaceuticals company. For example, the Healthcare pharmaceuticals company manufactures the drugs with the active support and technical guidance of the globally reputed pharmaceuticals company F. Hoffmann-La Roche Limited, Basel, Switzerland. ${ }^{6}$

15. As pharmaceutical industry is a separate industry from other industries. So pharmaceutical industry in Bangladesh have little or non-threatening competition.

16. Beximco Pharmaceuticals Company introduced the Metered Dose Inhalation Aerosols for the first time in Bangladesh by commissioning of its state of the art Metered Dose Inhalers (MDI) plant. The MDI plant has been designed in such a way to ensure highest possible quality at every stage of manufacturing and quality control. ${ }^{7}$

17. Some companies export medicines in many countries of the world. For example Beximco Pharmaceuticals Company limited has obtained the National Export Trophy (gold) for two consecutive years (1998-1999, 1999-2000). ${ }^{8}$ It is a good opportunity for the pharmaceuticals company in Bangladesh. The export markets for the pharmaceuticals products are Bhutan, Cambodia, Czech Republic, Germany, Iran, Iraq, Kenya, Malaysia, Mozambique, Myanmar, Nepal, Pakistan, Philippines, Russia, Singapore, South Korea, Sri Lanka, Thailand, Ukraine, Vietnam, and Yemen.

18. To ensure all the qualities, a highly dedicated academically sound and professionally competent team consisting of pharmacist, chemist, biochemists, microbiologists and engineers are using most modern and sophisticated equipment like high performance liquid chromatography, Gas chromatography, infrared spectrophotometer, Ultraviolet spectrophotometer, Homogenizer, in vitro bioavailability tester, Lung simulator, Disintegrator, Dissolution tester and many other latest computer aided quality control instruments and diseases.

19. Most of the companies in the pharmaceutical industry have the strong reputation in the market. These company such as are Square Pharmaceuticals Company limited, ACI Pharmaceuticals Company limited. Beximco Pharmaceuticals Company limited. 
20. Some of the company dominates the pharmaceuticals market in Bangladesh. $65 \%$ of the drugs used in Bangladesh are produced in Bangladesh. 35\% drugs are imported from the foreign countries.

21. The distribution systems of the pharmaceuticals company are strong in Bangladesh. Some medicines require quick transportation services. Otherwise it will damage. The companies have depots through which the company distributes their products all over the 64 districts in Bangladesh.

22. Bangladeshi pharmaceutical industry has strong sales force. The sales force has to deal with doctors. They have to motivate the doctors to prescribe the particular medicines. Otherwise a company cannot get success in these industries.

23. Some companies have strong research and development (R\&D) department. For example Beximco Pharmaceuticals employs a significant part of its resources in $R$ \& D that makes BPL a forerunner in the Bangladesh pharmaceuticals industry.

\section{Weaknesses}

1. The Bangladesh pharmaceutical industries are marred by the price regulation. Over a period of time, this regulation has reduced the pricing ability of companies. The DGDA (Directorate General of Drug Administration), which is the authority to decide the various pricing parameters, sets prices of different drugs, which leads to lower profitability for the companies. The companies, which are lowest cost producers, are at advantage while those who cannot produce have either to stop production or bear losses.

2. Bangladesh pharmaceutical sector has been marred by lack of product patent, which prevents global pharmaceutical companies to introduce new drugs in the country and discourages innovation and drug discovery. But this has provided an upper hand to the Bangladesh pharmaceutical industry.

3. Bangladesh pharmaceutical market is one of the least penetrated in the world. However, growth has been slow to come by. As a result, most of the pharmaceutical companies are relying on exports for growth.

4. Most of the pharmaceutical companies are in low financial positions, Due to the low financial position; it is not possible for some companies to install the latest technology in their premises.

5. Some of the pharmaceutical companies are in unskilled workforce. As a result these companies cannot minimize the cost of the production.

6. Due to very low barriers to entry, Indian pharmaceutical industry is highly fragmented with about 250 large manufacturing units and about 18,000 small units spread across the country. This makes Bangladesh pharmaceutical market increasingly competitive. The industry witnesses price competition, which reduces the growth of the industry in value term. To put things in perspective, in the year 2004 the industry actually grew by $8.6 \%$.

7. Most of the companies do not up to date their machineries, they perform their activities with the traditional machineries, and so it is difficult to maintain the quality of the medicines.

8. Some of the companies in this industry have the rented premises, as a result it add costs to the production. So the selling prices are increasing day by day.

9. Innovative effectiveness is low in our country due to the lack of the sophisticated equipment, lack of the capital, lack of the skilled manpower, and the lack of the professional in our country. 
10. Sometimes per unit cost of the medicines are higher than the imported medicines. The selling prices of the medicines become higher. So the domestics company has to fight with the multi-national companies.

11. The pharmaceutical sector attained a lower growth rate of $8.6 \%$ only during the 2004 as against $5.90 \%$ during the previous year. The lower growth rate of national pharmaceuticals market may be attributed to various factors such as lower public expenditure on health care. Natural calamities including floods, cyclones, epidemical diseases and lower agro crop harvest. The national pharmaceutical market growth and that of the company during the past few years.

12. Sometimes the selling price of the medicines are high in our country, it is beyond general customer's purchasing power.

13. Some pharmaceutical companies do not have any reputation in national or regional level; their products are not standard level.

14. The industries have to depend on foreign experts, technology, and raw materials. Due to the lack of the proper guidelines and the lack of the proper infrastructure facilities. The industry faces problems in marketing the products.

\section{Opportunities}

The SAARC region, Bangladesh stands out as a nation with a vast potential to become a leading pharmaceutical producer. Currently the country is producing mostly the drug formulations and nearly 250 units are engaged in this activity. The production by these units is adequate to meet almost 95 percent of the national requirements. With many large pharmaceutical units, the international manufacturing standards are largely absent amongst most of the small units. Regulatory procedures are yet to fully evolve. However companies like Beximco Pharmaceuticals, Square Pharmaceuticals, etc are now trying to adopt international manufacturing standards in their facilities.

New drug policy will help to expand pharmaceuticals industry

Lifesaving international-standard drugs are now being produced in Bangladesh and the country is about to achieve self-sufficiency in production of pharmaceuticals. Unveiling the plaque of an essential medicine-producing project here, The Essential Drugs Company Limited (EDCL) is already supplying drugs to different international organizations and also exporting abroad.

After implementation of the new policy, the industry would further expand and generate new job opportunities in the country. As a least developed country Bangladesh would get opportunity to produce patent medicines till 2016.

\section{BAPI Eyes to expand Pharmaceutical Markets}

Bangladesh is now exporting pharmaceuticals to about 30 countries and also eyeing expansion of more markets next year. Bangladesh had started exporting pharmaceuticals to some neighboring countries like Myanmar, Sri Lanka and Nepal in the 1980s and since then the export market expanding gradually.

Bangladesh Association of Pharmaceutical Industry (BAPI) said that the country would get the opportunity for exporting pharmaceuticals and other related items to India and China and other countries next year. Bangladesh is, among the 49 least developed countries (LDCs), which has the strongest base of manufacturing pharmaceuticals and so the country would get share of exporting the items after the global market will open up for all in the year 2005. Besides, the regular brands, Bangladesh are also exporting high-tech specialized products like inhalers, suppositories, Nasal Sprays, injectables and infusions. ${ }^{9}$ 


\section{Threats}

1. There are certain concerns over the patent regime regarding its current structure. It might be possible that the new government may change certain provisions of the patent act formulated by the preceding government.

2. The competition is increasing day by day in the pharmaceuticals sector. So the pharmaceutical companies have to face competition in the market.

3. Rising the cost of the wages; the basic wages, so it effect on total cost of the production and it will increase the selling prices of the medicines.

4. Increasing the interest rate, the interest rate of the bank is increasing day by day. So the investors do not agree to borrow from the bank

5. Threats from other low cost countries like China and Israel exist, so, differentiation in the contract manufacturing side may wane.

6. The short-term threat for the pharmaceutical industry is the uncertainty regarding the implementation of VAT. Though this is likely to have a negative impact in the shortterm, the implications over the long-term are positive for the industry.

7. There is a worrying development in the industry. Some companies appear to be focused on the maximization of short-run sales as opposed to long-run profits. This shift in focus is never good for the industry. Prices crash and marketing expenditure to finance gimmicks shoots up resulting in lower profits per unit of sale. Many companies panic at this stage and join the bandwagon of bad selling and marketing practices.

8. Bad selling practices in the pharmaceuticals industry by some companies are likely to dampen the market growth. In addition depreciation of the taka will raise the cost of imported raw materials.

9. The pharmaceuticals sector attained a lower growth rate of $8.6 \%$ only during the year 2004 as against $5.90 \%$ during the previous year. The lower growth rate of national pharmaceutical market may be attributed to various factors such as lower public expenditures on health care, natural calamities, including the floods, cyclones, epidemical diseases and lower agro-crop harvest.

10. Existing product become unpopular or unfashionable, the quality or the ingredients of the medicines are changing day by day. So the company has to face the losses. ${ }^{10}$

\section{SUGGESTION}

- The pharmaceuticals industry has to make commitment to the quality of the medicine, because medicines are directly related to life. The companies have to concern about this fact.

- So the pharmaceuticals industry should clearly identify the strengths, weaknesses, opportunities and threats. They have to point out of the strengths and take steps to utilize these strengths properly. The pharmaceutical industries have to challenge with the threats of the external environments. So they have to differentiate their product from other industry.

\section{CONCLUSION}

There still remains a lot of work in the field of SWOT analysis of the pharmaceuticals industry in Bangladesh. Several questions remain unanswered with regards to this emerging construct, some of which have been addressed within this paper, and some of which still remain to be explored. This research within the SWOT analysis has helped to shed some light in establishing what the characteristics of the SWOT analysis are. The SWOT analysis also provides the information about the pharmaceuticals industry in 
Bangladesh. There is some strength in the pharmaceuticals industry in Bangladesh. Government should take step to utilize this strength properly. Further researches will be pursued in this area by us in the hope of gaining a better understanding of SWOT analysis and its constituents, with the ultimate goal of providing a practical and functional measurement tool.

\section{REFERENCES}

[1] Shawon, S.A. 2011. Research Report: Pharmaceutical Industry of Bangladesh. IDLC Finance Limited.

[2] The Daily Star. 2011. Current scenario of Bangladesh pharma market. http:/ / bddrugs.com/detail.php?nid=13. 20 May 2013.

[3] Habib, M.A., Alam, M.Z. 2011. Business analysis of pharmaceutical farms in bangladesh: problems and prospects. Journal of Business and Technology. 4(1): 61-77.

[4] Bhuiyan, M.A.R., Moniruzzaman, and Sultana, S. 2011. Analysis of pharmaceutical industry of bangladesh: (it's challenges and critical success factors). Bangladesh Research Publications Journal. 5(2): 142-156.

[5] Saad, K.S. 2012. Research Report: An Overview of Pharmaceutical Sector in Bangladesh. BRAC EPL Limited.

[6] Healthcare Pharmaceuticals Limited (HLP). 2012. Partnering. http://www.hplbd.com/cakehplbd/pages/partnering. 22 May 2013.

[7] The News 2011.2 Today. News Rept. http:/ / www.newstoday.com.bd/index.php?option=details\&news_id=56395\&date=201203-17. 24 May 2013.

[8] Beximco Pharmaceuticals Limited (BPL). 2012. News Release. http://beximcopharma.com/latest-news/5335-beximco-pharma-enters-eu-market.html. 22 May 2013.

[9] Shafiuzzaman. S.M. 2004. Bangladesh Pharmaceutical Sector: A Vision of Success. BAPI.

[10] Rahman. W. 2012. Pharmaceutical Industry: Progress and Challenges. The Daily Star. 19 May 2013. 